\title{
Human Pancreatic Cancer Associated Antigen Detected by Monoclonal Antibody
}

\author{
Masao Kobari, Seiki Matsuno, Hidemi Yamauchi, \\ Toshio Sato, Toshio Kudo* and Takehiko Tachibana* \\ The First Department of Surgery, Tohoku University \\ Schook of Medicine, and *Department of Immunology, the \\ Research Institute for Tuberculosis and Cancer, Tohoku \\ University, Sendai 980
}

Kobari, M., Matsuno, S., Yamauchi, H., Sato, T., Kudo, T. and Tachibana, T. Human Pancreatic Cancer Associated Antigen Detected by Monoclonal Antibody. Tohoku J. exp. Med., 1986, 148 (2), 179-195— Monoclonal antibody F30 was produced by the fusion of murine myeloma cell line P3-X63-Ag8-653 with spleen cells from a BALB/C mouse immunized with established human pancreatic cancer cell line (PK-1) and the reaction specificity was analyzed. The antigen recognized by monoclonal antibody F30 was different from HLA-associated antigen, $\beta 2$-microglobulin, fetal bovine serum components, ferritin, AFP, or CEA. Monoclonal antibody F30 reacted with all of six pancreatic cancer cell lines established in our laboratory. Cross-reactivity was detected with a colon cancer cell line or an esophagus cancer cell line among various tumor cell lines tested. No reaction was detected with red blood cells, lymphocytes, or lymphoid and myeloid cell lines. By immunoperoxidase staining of frozen sections, the F30-defined antigen was detected not only on pancreatic cancer cell membrane but also on other adenocarcinomas. In addition, the monoclonal antibody F30 had a more widespread distribution on normal epithelial cells in the gastrointestinal organs, respiratory system, and urinary system. F30-defined antigen was composed of two protein components with molecular weight of 190 and $160 \mathrm{~K}$. It was indicated that the antigen was an integral protein in the cell membrane since the antigen was not detected in the spent culture medium of antigen-positive cells.

monoclonal antibody; pancreatic cancer cell lines; pancreatic cancer associated antigen

Recent advances in immunological techniques have promoted the application

Received September 26, 1985 ; accepted for publication December 5, 1985.

Abbreviations used in this paper: McAb, monoclonal antibody; AFP, alphafeto protein ; CEA, carcinoembryonic antigen ; SDS-PAGE, sodium dodecyl sulphate polyacrylamide gel electrophoresis; PBS, phosphate-buffered saline; MEM, minimum essential medium; IIF, indirect immunofluorescence, ELISA, enzyme-linked immunosorbent assay ; BSA, bovine serum albumin; RPMI, Roswell Park Memorial Institute; NP-40, Nonidet P 40 ; PMSF, phenylmethane sulfonyl fluoride ; Ig, immunoglobulin; IAA, iode acetic acid ; $\mathrm{BPB}$, bromophenol blue; FITC, fluorescein isothiocyanate. 
of antibodies against tumor-associated antigens, such as AFP or CEA, for the diagnosis and management of malignant diseases. The measurement of serum antigen level has been demonstrated to be one of the useful methods not only to detect the presence of malignancy but to monitor the disease state after each therapeutic procedure. A number of human pancreatic cancer-associated antigens have already been described and analyzed both experimentally and clinically using polyclonal xenoantisera (Banwo et al. 1974; Schultz and Yunis 1976; Gelder et al. 1978; Holyoke et al. 1979; Hobbs 1980; Zamcheck 1981). However, the clinical application of these antigens for the early detection of pancreatic cancer has not yet been performed successfully because of the wide cross reactivity and the low sensitivity of the antisera (Banwo et al. 1974 ; Schultz and Yunis 1976; Gelder et al. 1978; Hobbs 1980). On the other hand, since the introduction of somatic cell hybridization (Köhler and Milstein 1975), a number of monoclonal antibodies against a variety of human tumors, such as melanoma (Steplewski et al. 1979; Liao et al. 1982 ; Natali et al. 1982), lung cancer (Kasai et al. 1981 ; Brown and Moore 1982; Mazauric et al. 1982 ; Bernal and Speak 1984), breast cancer (Menard et al. 1983 ; Papsidero et al. 1983), colorectal cancer (Koprowski et al. 1979 ; Atkinson et al. 1982 ; Thompson et al. 1983 ; Kaszubowski et al. 1984), and prostate and bladder cancer (Starling et al. 1982 ; Masuko et al. 1985) have been produced. It is expected that these monoclonal antibodies can be more useful for evaluating the distribution of organ-specific antigens or tissue-associated antigens and for detecting potential tumor-associated antigens in cancer patients because of the high reaction specificity. These circumstances urged us to establish human pancreatic cancer cell lines and to elaborate monoclonal antibodies specific for pancreatic cancer cells.

In the present report, we describe the production and the characterization of the monoclonal antibody F30 which is reactive with pancreatic cancer cell PK-1. And we evaluate the reaction specificity of this antibody with a panel of various tumor cell lines and frozen sections of tumor and normal tissues, and further estimate the molecular profile of the antigens recognized by the F30.

\section{Materials and Methods}

Cell lines used for immunization and screening of monoclonal antibody

Human pancreatic cancer cell line PK-1 established in our laboratory (Kobari et al. 1984) was used for the immunization. This cell line was initiated from a papillotubular adenocarcinoma obtained from a liver metastasis of the carcinoma of the pancreatic body. After trypsinization, PK-1 cells were washed three times with PBS, and $1 \times 10^{7}$ cells in 0.5 $\mathrm{ml}$ PBS were prepared for intraperitoneal immunization. Human cell lines used for the screening of monoclonal antibodies were as follows : pancreatic cancer cell lines PK-8, PK-9, PK-12, PK-14, PK-16 were established in our laboratory ; gastric cancer cell lines KATO-3 and M74-1, colon cancer cell lines S7512 and M7609, and esophagus cancer cell lines TE-1 and TE-4, were kindly provided by Dr. S. Nishihira; lung cancer cell lines LK-2-18 and LK-2-51 and melanoma cell line Mel-2-42 were kindly provided by Dr. S. Kobayashi; breast cancer cell line MMK-K was established in our laboratory from xenografted breast 
cancer in nude mice and another breast cancer cell line CRL-1500 was purchased from Flow Laboratories (North Ryde, N.S.W., Australia); hepatoma cell line HuH-7 was kindly provided by H. Nakabayashi (Nakabayashi et al. 1984) and HT-1 was established in our laboratory from xenografted hepatoma Li-7 in nude mice kindly provided by Dr. S. Hirohashi (Hirohashi et al. 1979) ; other cell lines used in this study have been maintained in our laboratory.

\section{Production of monoclonal antibodies}

Immunization and somatic cell hybridization. BALB/C mice were immunized intraperitoneally with two bi-weekly injections of PK-1 cells and followed by a final booster intraperitoneal injection 3 days prior to the cell fusion. Immune spleen cells $\left(5 \times 10^{7}\right)$ were fused with $5 \times 10^{6} \mathrm{P} 3$-X63-Ag8-653 murine myeloma cells in the presence of $45 \%$ polyethylene glycol 1,000 in MEM according to the method of Köhler and Milstein (Köhler and Milstein 1975) with some modifications.

Selection of hybridoma. After fusion, cells were cultured in HAT medium (hypoxantine, aminopterin, thymidine) at $37^{\circ} \mathrm{C}$ in $5 \% \mathrm{CO}_{2}$ in humidified atmosphere. Cloning of hybrid cells reactive with the target PK-1 cells was carried out by the limiting dilution at the cell density ranging from $5 / \mathrm{ml}$ to $10 / \mathrm{ml}$ with thymocytes as a feeder layer and repeated 2 or 3 times. Cloned hybrid cells secreting antibody reactive with PK-1 cells by IIF were implanted into BALB/C mice intraperitoneally to obtain sera and ascites. The monoclonal antibody produced by one cloned hybridoma, designated F30 was used in the present study.

\section{Antibody detection assays}

Indirect immunofluorescence. The culture supernatant of hybridoma was used for the evaluation of the anti-PK-1 cell antibody. At first, $5 \times 10^{5} \mathrm{PK}-1$ cells in each tube were incubated with $50 \mu \mathrm{l}$ of hybridoma supernatant at $37^{\circ} \mathrm{C}$ for $30 \mathrm{~min}$. After three washes with old PBS containing $0.01 \%$ sodium azide, the cells were incubated with $50 \mu \mathrm{l}$ of FITC conjugated anti-mouse $\mathrm{Ig}\left(\mathrm{MBL}\right.$, Nagoya) at $37^{\circ} \mathrm{C}$ for $30 \mathrm{~min}$. After three washes, the membrane fluorescence was determined with an epi-illumination fluorescence microscope (Zeiss, West Germany). The membrane CEA of cell lines was also assayed by IIF using rabbit anti-CEA immunoglobulin (DAKO-Immunoglobulins, Copenhagen, Denmark) and FITC conjugated anti-rabbit IgG (Hoechst Behring Institute, Marburg-Lahn, FRG).

Enzyme-linked immunosorbent assay (ELISA). ELISA was carried out for the screening of the immunoglobulin secretion of hybridoma into the culture supernatant. Target PK-1 cells, $5 \times 10^{5}$ per tube, were first incubated with $50 \mu 1$ of the hybridoma culture supernatant diluted to $1 / 50$ with the medium at $37^{\circ} \mathrm{C}$ for $30 \mathrm{~min}$. After three washes with cold PBS, the cells were incubated at $37^{\circ} \mathrm{C}$ for $30 \mathrm{~min}$ with $50 \mu \mathrm{l}$ of peroxidase-conjugated anti-mouse Ig (DAKO-Immunoglobulins, Copenhagen, Denmark) at dilution of 1/500 in 1\% BSA containing RPMI 1640 medium. After 4 washes with cold PBS, $100 \mu$ l of substrate solution ( $10 \mathrm{ml}$ of $0.1 \mathrm{M}$ citrate buffer, $\mathrm{pH} 4.5,10 \mathrm{mg}$ of O-phenylenediamine (Sigma Chemical Company, St. Louis, MO, USA) $4 \mu \mathrm{l}$ of $30 \% \mathrm{H}_{2} \mathrm{O}_{2}$ stock solution) was added to the tube and incubated at $37^{\circ} \mathrm{C}$ for $30 \mathrm{~min}$ in the dark. Enzymatic reaction was stopped by adding $50 \mu \mathrm{l}$ of $6 \mathrm{~N}-\mathrm{H}_{2} \mathrm{SO}_{4}$ and the optimal density of the colored supernatant was measured at $500 \mathrm{~nm}$ by a spectrophotometer.

\section{Absorption tests}

Reactivities of F30 with various tumor cell lines were examined first by IIF. And then the following absorption tests were performed for cell lines when IIF were negative.

ELISA. F30 (1/50 in medium) was absorbed with various tumor cell lines for $30 \mathrm{~min}$. at $37^{\circ} \mathrm{C}$ and another $30 \mathrm{~min}$. at $4^{\circ} \mathrm{C}$. After centrifugation, the remaining activity of $\mathrm{F} 30$ was determined with target PK-1 cells by ELISA as mentioned before.

Indirect immunofluorescence. McAb F30 (diluted to 1/40 in medium) was absorbed with a CEA producing gastric cancer cell line, KATO-3 (Sekiguchi et al. 1978) for 30 min. 
at $37^{\circ} \mathrm{C}$ and then for $30 \mathrm{~min}$ at $4^{\circ} \mathrm{C}$. The absorbed $\mathrm{F} 30$ was also tested for the remaining activity to $\mathrm{PK}-1$ cells by IIF.

Absorption test with PK-1 cell spent culture medium. One volume of diluted F30 (1) 25) was mixed with an equal volume of the concentrated serum free spent culture medium of PK-1 cells and allowed to stand for $18 \mathrm{hr}$ at $4^{\circ} \mathrm{C}$. The mixture was tested for the remaining antibody activity by ELISA.

\section{Purification of monoclonal antibody and iodination}

The isotype of monoclonal antibody was determined by the double immunodiffusion method using goat anti-mouse immunoglobulins (Meloy laboratories, Inc. Diagnosis Division, Springfield, VA., USA). The isotype of McAb F30 was $\operatorname{IgG}_{2 b}$. McAb F30 was purified from mouse ascites by the use of Protein A Sepharose CL-4B (Pharmacia Fine Chemicals, Uppsala, Sweden). Purified McAb F30 was labeled with ${ }^{125} \mathrm{I}$ by the chloramine$\mathrm{T}$ method as described by McConahey et al. (McConahey and Dixon 1966) yielding proteins with specific activities of $2.4 \times 10^{6} \mathrm{cpm} / \mu \mathrm{g}$ protein.

\section{Binding inhibition tests}

For competitive binding inhibition tests, $50 \mu \mathrm{l}$ of several kinds of unlabeled antibodies (10 to 50 fold diluted sera) were incubated with target PK-1 cells for 30 min at $37^{\circ} \mathrm{C}$ prior to addition of ${ }^{125} \mathrm{I}$-labeled McAb F30 $(50 \mu \mathrm{l})$. After incubation with the labeled McAb F30 for $30 \mathrm{~min}$ at $37^{\circ} \mathrm{C}$, the target PK-1 cells were washed three times with PBS and counted for radioreactivity. Antibodies used for these studies were: anti-HLA (Hoechst Behring Institute, Marburg-Lahn, FRG), anti-HLA-DR (a gift from Dr. Katagiri, Department of pathology, Asahikawa Medical college, Hokkaido), anti- $\beta 2$-microglobulin (DAKO Immunoglobulins, Copenhagen, Denmark), anti-CEA immunoglobulin (DAKO), anti-AFP immoglobulin (DAKO), anti-human IgM monoclonal antibody KM-8 (a gift of Dr. Ono, Department of Immunology, The Research Institute for Tuberculosis and Cancer, Tohoku University, Sendai).

\section{Double immunofluorescent staining}

PK-1 cells were incubated with undiluted McAb F30 and washed with PBS. The cells were then incubated with FITC conjugated anti-mouse IgG at $37^{\circ} \mathrm{C}$ for $2 \mathrm{hr}$ in order to induce redistribution and cap-formation of the antigen reacting with FITC labeled $\mathrm{McAb}$ F30 over the surface of PK-1 cells. Next, rabbit anti-CEA (DAKO) and rhodamine conjugated goat anti-rabbit IgG (E-Y Laboratories, San Mateo, CA., USA) were reacted with target cells at $4^{\circ} \mathrm{C}$ for $2 \mathrm{hr}$ in order to avoid further redistribution of the relevant antigen.

\section{Enzyme treatment}

PK-1 cells were incubated with enzymes at $37^{\circ} \mathrm{C}$ for one $\mathrm{hr}$ and then examined for the expression of the F30 reactve antigen by IIF or absorption tests with ELISA. Enzymes used in this assay were neuraminidase (Hoechst), trypsin (GIBCO, Grand Island, NY, USA), pronase (Kaken Co., Ltd, Tokyo), deoxyribonuclease (Millipore Corporation, Freehold, N.J., USA), and collagenase (Millipore Corporation).

\section{Immunoprecipitation and SDS-PAGE}

Radioiodination of cell membrane. Viable PK-1 cell suspension at $3 \times 10^{8}$ cells in 0.1 $\mathrm{ml}$ PBS was mixed with $100 \mu \mathrm{l}$ of lactoperoxidase (Sigma chemical Co.) at $1 \mathrm{mg} / \mathrm{ml}$ in PBS, $\mathrm{pH} 7.3,2 \mathrm{mCi}$ of ${ }^{125} \mathrm{I}-\mathrm{NaI}$ in $20 \mu \mathrm{l}$, and finaly $100 \mu \mathrm{l}$ of freshly prepared $\mathrm{H}_{2} \mathrm{O}_{2}$ solution $(0.03 \%)$ in PBS. The mixture was left at $30^{\circ} \mathrm{C}$ for $5 \mathrm{~min}$. Aliquots of lactoperoxidase and freshly prepared $\mathrm{H}_{2} \mathrm{O}_{2}$ solution were then added again and incubated for $5 \mathrm{~min}$. This step was repeated three times. After 5 minutes' incubation, the cells were washed three times with PBS and resuspended in $0.5 \mathrm{ml}$ PBS.

A subconfluent monolayer of PK-1 cells was also intrinsically radiolabeled with 300 
$\mu \mathrm{Ci}$ of ${ }^{35} \mathrm{~S}$-methionine in MEM without unlabeled methionine overnight at $37^{\circ} \mathrm{C}$ (Bumol and Reisfeld 1982). Labeled cells were harvested with $0.25 \%$ trypsin treatment, washed three times and suspended in $0.5 \mathrm{ml}$ PBS.

Membrane extraction. A half ml of extraction buffer (1\% NP-40, $1 \mathrm{mM}$ PMSF in PBS, $\mathrm{pH} 7.3$ ) was added to $0.5 \mathrm{ml}$ of cell suspension in PBS and vigorously mixed on ice for 30 min. Extracts were cleared by centrifugation once at $2,000 \times \mathrm{g}$ for 15 minutes and again at $25,000 \times \mathrm{g}$ for $1 \mathrm{hr}$.

Immunoprecipitation. One $\mathrm{ml}$ of $10 \%$ Zysorbin (fixed and killed protein-A bearing staphylococcus aureus; Zymed Labo., Burlingame, CA, USA) was washed 3 times with washing buffer $(0.1 \%$ BSA, $0.02 \%$ sodium azide, $0.5 \%$ NKP- $40,0.1 \%$ SDS in PBS, pH 8 . 6). To this pelleted Zysorbin, $1 \mathrm{ml}$ of anti-mouse $\mathrm{Ig}$ was added. After incubation for 30 min at $37^{\circ} \mathrm{C}$, the Zysorbin was washed 4 times with washing buffer (WB). Next, F30 or anti-human IgM McAb, KM-8 as a control were added to the zysorbin pellet and incubated for $1 \mathrm{hr}$ at $37^{\circ} \mathrm{C}$. After washing 3 times with $\mathrm{WB},{ }^{125}$ I-labeled cell extract or ${ }^{35} \mathrm{~S}$-methionine labeled cell extract was added to the Zysorbin pellet coupled with McAb and incubated overnight at $4^{\circ} \mathrm{C}$ with a continuous rotation.

$S D S-P A G E$. The Zysorbin-antigen complex was washed 3 times with $\mathrm{WB}$, and then the pellet was resuspended in $50 \mu \mathrm{l}$ of sample buffer $(4 \mathrm{M}$ urea, $20 \mathrm{mM} \mathrm{IAA}, 0.25 \% \mathrm{BPB}, 2 \%$ SDS, $50 \%$ glycerol with or without $0.1 \%$ 2-mercaptoethanol in $0.02 \mathrm{M}$ phosphate buffer). This mixture was heated at $100^{\circ} \mathrm{C}$ for $2 \mathrm{~min}$. Electrophoresis on $7 \%$ polyacrylamide gel was carried out as described by Galloway et al. (1981) and followed by autoradiography.

\section{Indirect immunofluorescence of tissue sections}

At the beginning, $4 \mu \mathrm{m}$ cryostat sections were pretreated with $10 \%$ normal horse serum for $15 \mathrm{~min}$ at room temperature. After washing of sections with PBS, McAb F30 (not diluted) was added on tissue sections. Preculture medium or anti-human IgM McAb KM-8 was used as a control. After incubation for $30 \mathrm{~min}$ at $37^{\circ} \mathrm{C}$ and rinsing in $\mathrm{PBS}$, sections were incubated with biotinylated horse anti-mouse Ig antisera (Vector Labs Inc. Burlingame, CA., USA) at 1/100 dilution for $30 \mathrm{~min}$ at room temperature. After rinsing in PBS sections were incubated with FITC conjugated avidin at $1 / 50$ dilution for 30 min at room temperature, and examined under the epi-illumination fluorescence microscope.

In immunoperoxidase staining using $\mathrm{ABC}$ system, biotinylated secondary antibody and next avidin-biotin conjugated horseradish peroxidase (Vector Labs) were incubated for 30 min at $37^{\circ} \mathrm{C}$ after the slides were first incubated with McAb F30. Then the slides were incubated with enzyme substrate solution (30 mg diaminobenzidine (Sigma Chemical Co.) and $0.15 \mathrm{ml}$ of $5 \% \mathrm{H}_{2} \mathrm{O}_{2}$ in $150 \mathrm{ml}$ of $0.05 \mathrm{M}$ tris buffer $\mathrm{pH} 7.2$ ) for up to $10 \mathrm{~min}$ at room temperature and examined for staining.

\section{Results}

By the fusion of $\times 63$ myeloma cell with spleen cells of a BALB $/ \mathrm{C}$ mouse immunized with pancreatic cancer cell line PK-1, 23 colonies secreting antibodies reactive with PK-1 cells were obtained. After cloning of these colonies, three clones specifically reactive with PK-1 cells were selected. Among these colonies C-8 was abandoned because of low reactivity, F-11 was lost by contamination, and only clone F30 was maintained. Culture supernatant of this clone F30 was used as $\mathrm{McAb}$ to pancreatic cancer in this study. Clear immunofluorescent staining pattern was visible on the membrane of PK-1 cells in IIF with McAb F30 (Fig. $1)$. 
Reactivity of anti-PK-1 cell monoclonal antibody F30 with various tumor cell lines

Reactivity of McAb F30 with various tumor cell lines was tested by IIF (Table 1). Six established pancreatic cancer cell lines were all reactive with F30. Other reactive cell lines were a colon cancer, M7609 and an esophagus cancer, TE-1 (Nishihira et al. 1979). The following lymphoblastoid cell lines and normal lymphocytes were non-reactive: MOLT-4F ( $\mathrm{T}$ cell line); Raji (B cell line); P3HR-1 (EBV producing B cell line); and THP-1 (monocytic leukemia cell line). Although pancreatic cancer cell lines were all CEA positive together with gastric, colon, esophagus, and breast cancer cell lines, McAb F30 was not necessarily

TABLE 1. Indirect immunofluorescence reactivity of McAb F30 with various tumor cell lines

\begin{tabular}{|c|c|c|c|}
\hline Cell lines & & McAb F30 & Anti-CEA \\
\hline \multirow[t]{6}{*}{ Pancreatic cancer } & PK-1 & \# & m \\
\hline & PK-8 & + & \# \\
\hline & PK-9 & H & \# \\
\hline & PK-12 & + & + \\
\hline & PK-14 & H & \# \\
\hline & PK-16 & + & + \\
\hline \multirow[t]{2}{*}{ Gastric cancer } & KATO-3 & - & \# \\
\hline & M74-1 & - & H \\
\hline \multirow[t]{2}{*}{ Colon cancer } & S7512 & - & \# \\
\hline & M7609 & H & H \\
\hline \multirow[t]{2}{*}{ Lung cancer } & LK-2-18 & \pm & \\
\hline & LK-2-51 & - & \\
\hline \multirow[t]{2}{*}{ Brain tumor } & HBT-5 & - & - \\
\hline & Marcus & - & - \\
\hline Melanoma & Mel-2-42 & - & - \\
\hline \multirow[t]{2}{*}{ Esophagus cancer } & TE-1 & + & H \\
\hline & TE-4 & \pm & \\
\hline \multirow[t]{2}{*}{ Breast cancer } & MMK-K & - & + \\
\hline & CRL-1500 & - & \\
\hline \multirow[t]{4}{*}{ Lymphoblastoid cells } & MOLT-4F & - & \\
\hline & Raji & - & - \\
\hline & THP-1 & - & - \\
\hline & P3HR-1 & - & \\
\hline \multirow[t]{2}{*}{ Hepatoma cells } & HuH-7 & - & \\
\hline & HT-1 & - & \\
\hline Fibroblasts & HEL & \pm & - \\
\hline Normal lymphocytes & & - & - \\
\hline
\end{tabular}




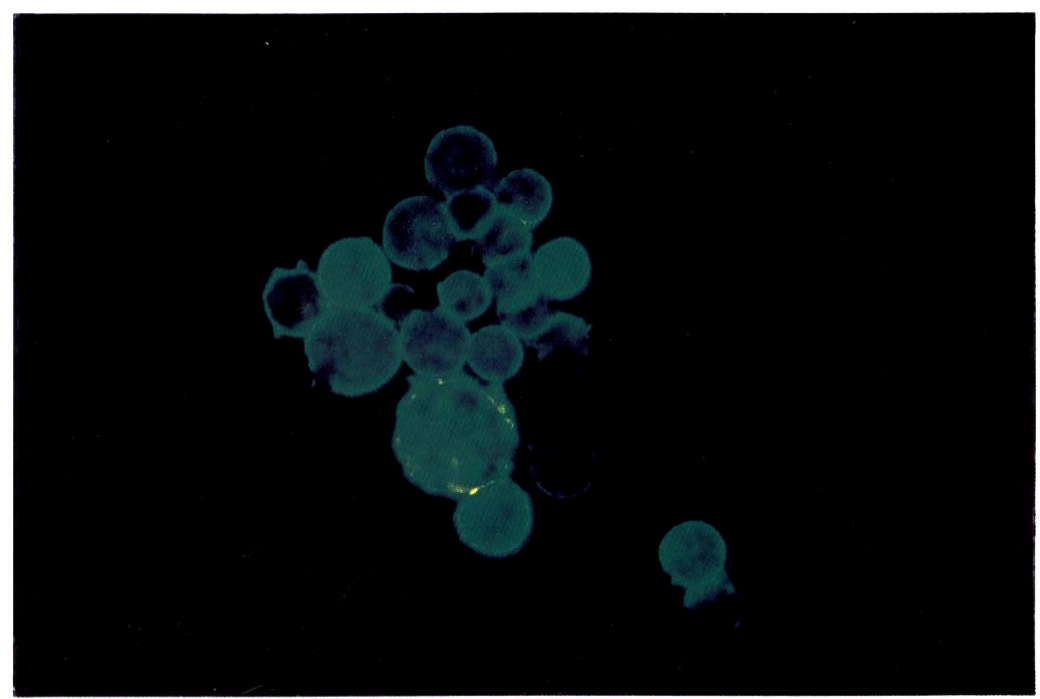

Fig. 1. Indirect immunofluorescent staining pattern of PK-1 cells with McAb F30 and FITC conjugated anti-mouse Ig. Clear circular fluorescent staining was visible on the surface of PK-1 cells.

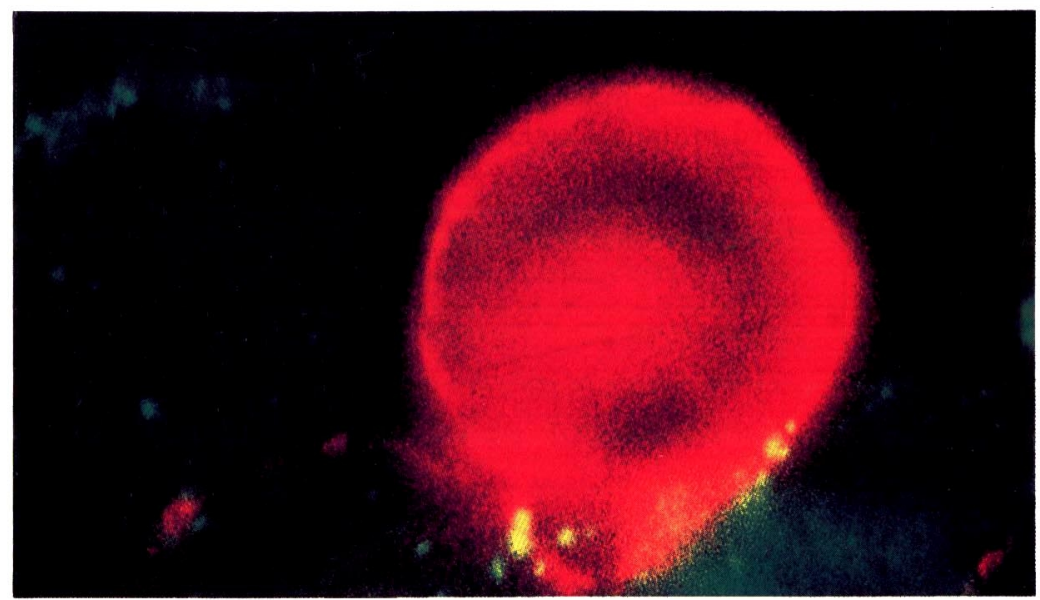

Fig. 2. Failure of co-capping of CEA (red staining with rhodamine) with the antigen (green staining with FITC) which formed the cap on the surface of PK-1 cell by reacting with McAb F30. The field was slightly shifted horizontally between the exposures for green vs red fluorescence. Cap forming green staining was localized on the upper portion of the surface of the cell which was not identical with circular red staining CEA. 
reactive with CEA positive cell lines other than pancreatic cancer cell lines, such as gastric cancer cell lines KATO-3 and M74-1 (Sekiguchi et al. 1978), colon cancer cell line, S7512 (Machida et al. 1977), and breast cancer cell line (MMK-K). As to a lung cancer cell line LK-2-18, esophagus cancer cell line TE-4, and human embryonal lung fibroblast HEL, very weak reaction with F30 was observed by IIF.

\section{Absorption tests}

As to tumor cell lines whose IIF reactivities with McAb F30 were not clear,

Table 2. Absorption capacity of various cell lines for McAb F30 (ELISA)

\begin{tabular}{lc}
\hline \multicolumn{1}{c}{ Cell lines } & Relative expression of antigen $(\%)$ \\
\hline PK-1 & 100 \\
\hline M7609 (colon cancer cell line) & 100 \\
LK-2-18 (lung cancer cell line) & 10 \\
TE-1 (esophagus cancer cell line) & 53 \\
TE-4 (esophagus cancer cell line) & 100 \\
HEL (human embryonal lung fibroblast) & 126 \\
MJ-19 (adult fibroblast) & 10 \\
Humam RBC (type AB) & 0 \\
\hline
\end{tabular}

Relative expressions of antigen are presented as percentage of absorption with various cell lines compared to the absorption with PK-1 cells estimated by enzymelinked immunosorbent assay using PK-1 cells as target.

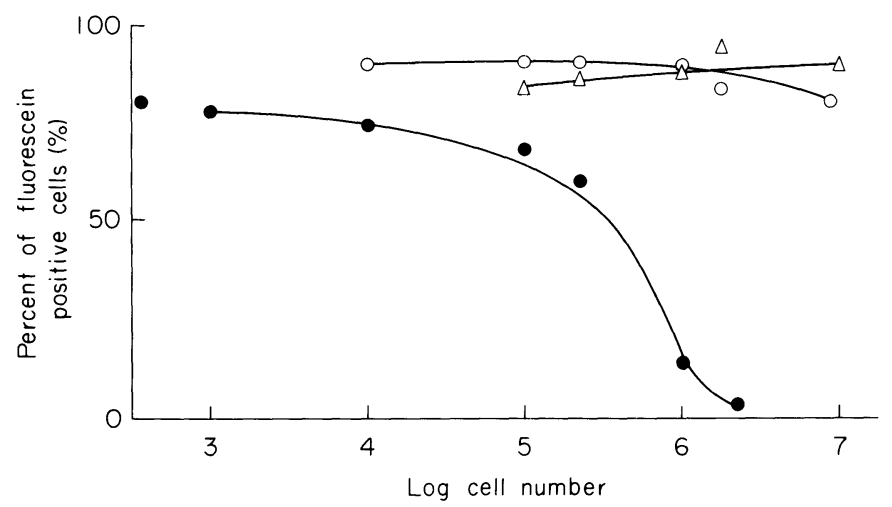

Fig. 3. Absorption test of McAb F30 with CEA producing gastric cancer cell line KATO-3 determined by indirect immunofluorescence.

Gastric cance cell lines KATO-3 (CEA positive and F30 reactive antigen negative, $\bigcirc-\mathrm{O})$, PK-1 cell line (CEA and F30-reactive antigen positive control, $-\bullet$ ), or MOLT-4F (CEA and F30-reactive antigen negative control, $\triangle-\triangle$ ) was incubated with a given amount of McAb F30 for 30 $\min$ at $37^{\circ} \mathrm{C}$ and for $30 \mathrm{~min}$ at $4^{\circ} \mathrm{C}$. After centrifugation the remaining activity of $\mathrm{McAb}$ was assayed for indirect immunofluorescent staining of the target PK-1 cells and percent of positive cells were counted. 
TABle 3. Binding of ${ }^{125} I$-labeled McAb F30 to PK-1 target cells following preincubation of the target with designated unlabeled antibodies

\begin{tabular}{lc}
\hline \multicolumn{1}{c}{ Unlabeled antibodies } & Binging $(\%)$ \\
\hline Control buffer & 100 \\
\hline McAb F30 & 9.6 \\
Anti-CEA & 84 \\
Anti-AFP & 86 \\
Anti-ferritin & 92 \\
Anti-HLA-DR & 91 \\
Anti-HLA & 99 \\
Anti- $\beta 2$-microglobulin & 93 \\
KM-8 (anti-human IgM McAb) & 93 \\
\hline
\end{tabular}

Results are presented as the percentage of binding compared to the binding of the labeled antibody after preincubation of target cells with the control buffer.

the capacity of these cell lines to absorb McAb F30 was tested by ELISA (Table 2). CEA positive colon cancer cell line M7609, esophagus cancer cell lines TE-1, TE-4 and embryonal fibroblast HEL absorbed F30 at the same level as PK-1 cells. On the other hand, lung cancer cell line LK-2-18 and human adult fibroblast MJ-9 did not show significant absorption.

To clarify whether or not the specificity of McAb F30 is directed to an antigenic determinant of CEA molecule, the absorption capacity of CEA positive gastric cancer cell line KATO-3 was estimated by IIF (Fig. 3). McAb F30 was not absorbed by CEA positive cells at all. In addition, it was tested whether CEA formed co-cap with the F30 defined antigen. As shown in the figure 2, F30 antigen was stained green and capped over the upper surface of PK-1 cell (upper left of the figure), while CEA was stained red and destributed equally circular over the cell surface (right part of the figure). These data clearly indicate that F30 defined antigen is not identical with CEA.

\section{Binding inhibition tests}

Next, it was studied whether the binding of McAb F30 was inhibited by antibodies to several other surface antigens to clarify the relationship between the F30 defined antigens and other surface antigens. For this purpose, a panel of unlabelled antibodies as competitors were preincubated with target PK-1 cells before reaction with ${ }^{125} \mathrm{I}$-labeled McAb F30 (Table 3). The binding of McAb F30 was inhibited neither by control McAb KM-8 (anti-human $\operatorname{IgM}$ ) nor by other antibodies to CEA, AFP, ferritin, $\beta 2$-microglobulin, and HLA. So it was suggested that F30 was not reactive with other antigenic determinants, at least such as, CEA, AFP, ferritin, HLA-DR-Ag, 2-microglobulin, and HLA. 
Absorption test with PK-1 cell spent culture medium

In order to examine whether PK-1 cells secreted F30 reactive antigen, absorption test with the concentrated serum free PK-1 cell spent culture medium

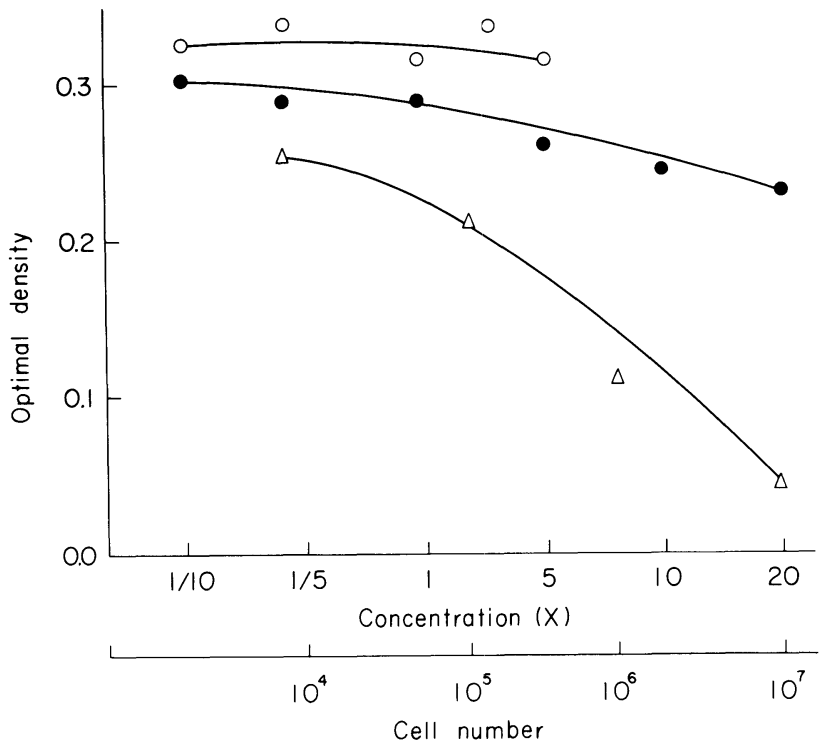

Fig. 4. Absorption test with PK-1 cell spent culture media. Enzyme-linked immunosorbent assay was used for determination of McAb F30 activity remaining after absorption with $\mathrm{PK}-1$ cell spent culture media at various concentration or PK-1 cells. $\bigcirc-\bigcirc$, PK-1 cell spent culture medium with $10 \%$ FCS ; $-\bullet$, PK-1 cell spent culture medium serum free ; $\triangle \longrightarrow \triangle$, PK-1 cells.

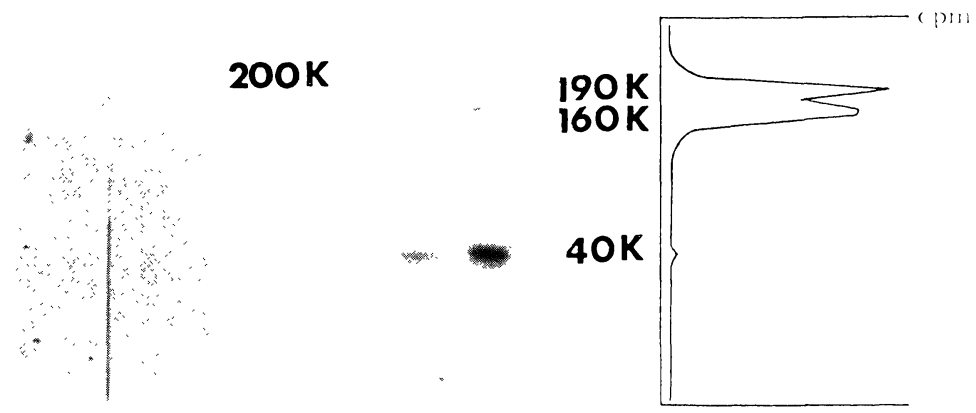

Fig. 5. Immunoprecipitation and SDS-PAGE analysis of pancreatic cancer cell PK-1 extract antigens detected by McAb F30. ${ }^{125}$ I-labeled (lanes 3 and 4) or ${ }^{35}$ S-methionine labeled (lanes 1 and 2) PK-1 cell extracts were immunoprecipitated either with control anti-human IgM McAb KM-8 (lanes 1 and 3) or with McAb F30 (lanes 2 and 4) using anti-mouse Ig coupled Zysorbin (fixed and killed protein-A bearing staphylococcus aureus) and analyzed by SDSPAGE. Radiocounting pattern of sliced gels $(1 \mathrm{~mm})$ was shown on the right part of the figure. 
TABLE 4. F30 reactive antigen expression of PK-1 cells after treatment with enzymes

\begin{tabular}{lccc}
\hline Enzymes & Concentration & IIF* & $\begin{array}{c}\text { Antigen expression in } \\
\text { ELISA } \dagger(\%)\end{array}$ \\
\hline Control PBS & & $\#$ & 100 \\
\hline Neuraminidase & $1 \mathrm{u}$ & $+\sim \#$ & 69 \\
& $0.1 \mathrm{u}$ & $\#$ & 95 \\
Trypsin & $2.5 \%$ & $+\sim \#$ & 75 \\
& 0.25 & $\#$ & 100 \\
Pronase & $15 \mathrm{u}$ & $\#$ & 100 \\
DNase & $64 \mathrm{u}$ & $\#$ & 100 \\
Collagenase & $93 \mathrm{u}$ & $\#$ & 100 \\
\hline
\end{tabular}

* Inidrect immunofluorescence using McAb F30 and FITC labeled anti-mouse Ig

$\dagger$ Antigen expression of PK-1 cells after treatment with enzymes was estimated from their capacity to absorb McAb F30. The antibody activity remained after absorption was measured by ELISA.

was performed by ELISA (Fig. 4). The activity of F30 against PK-1 was not affected after absorption with 20 times concentrated spent culture medium indicating that PK-1 cells secreted no F30 reactive antigen or, if any, it was undetectable amount in the medium.

\section{Immunoprecipitation and SDS-PAGE}

Results obtained by immunoprecipitation analysis of the detergent extract of ${ }^{125}$ I-labeled PK-1 cells are shown in Fig. 5. McAb F30 detected two specific protein components of molecular weight of $190 \mathrm{~K}$ and $160 \mathrm{~K}$ dalton. The component of $40 \mathrm{~K}$ was not specific because this component was also detected in the immunoprecipitate with control McAb KM-8. These two specific components and one non-specific component were more clearly shown in $\gamma$-counting pattern of sliced gels (the right part of Fig. 5). Specific components gave strong counts while the count of non-specific one was weak.

Analysis of detergent extract from PK-1 cells intrinsically labelled with ${ }^{35}$ S-methionine by immunoprecipitation and SDS-PAGE demonstrated the presence of a component of $200 \mathrm{~K}$ dalton which reacted with McAb F30 (Fig. 5). This component is slightly larger than $190 \mathrm{~K}$ component of ${ }^{125} \mathrm{I}$-labelled cell extract. It is not clear whether these two components are identical.

\section{Enzyme sensitivity of $F 30$ reactive antigen on $P K-1$ cells}

The antigen detected by McAb F30 was found to be resistant to the treatment with several enzymes including neuraminidase and proteases (Table 4). The F30 reactive antigen expression was moderately decreased by the treatment with neuraminidase or trypsin only when both were used at very high concentrations. Deoxyribonuclease and collagenase had no marked influence on the antigen 
TABLE 5. Immunoreactivity of normal and malignant tissue sections with McAb F30

\begin{tabular}{lcc}
\hline \multicolumn{1}{c}{ Specimen } & Immunoperoxidase staining & IIF \\
\hline Skin & + & \\
Esophagus & $H$ & \\
Stomach & - & \\
Duodenum & + & \\
Jejunum & + & \\
Colon & + & \\
Liver & - & \\
Gallbladder & + & \\
Common bile duct & + & \\
Pancreas & + & \\
Lung & - & \\
Trachea & + & \\
Heart & - & \\
Thyroid gland & - & $1 / 1$ \\
Kidney & + & \\
Urinary bladder & + & \\
Prostate & - & \\
Adrenal gland & + & \\
Spleen & - & \\
Lymph node & - & \\
\hline Pancreatic cancer & $1 / 1^{*}$ & \\
Gastric cancer & & \\
Colon cancer & & \\
Breast cancer & & \\
\hline
\end{tabular}

Cryostat sections of frozen tissues were examined by indirect immunofluorescent staining using biotin-avidin system and immunoperoxidase staining using ABC system as described in Materials and Methods.

* number of positive staining/number of tissue sections tested.

expression.

Immunoreactivity of normal and malignant tissue sections with McAb F30

Immunofluorescence staining with biotin-avidin system was performed using fresh frozen sections because the ordinary IIF staining on formalin fixed paraffinembedded sections could not show the positive reaction (Table 5). Immunoperoxidase staining was next performed for histological analysis. In pancreatic cancer, all specimens showed positive reactions on their cancer cell membranes. There were no reactions in the surrounding interstitial tissue. Similar reactions on the cancer cell membranes were detected in stomach cancer, colon cancer, and breast cancer. In the distribution analysis of normal tissues, McAb F30 reacted 
at first with cell membranes of squamous epithelium of the skin and esophagus. Though the reaction was lost in the stomach, it was found again on glandular epithelial cell membranes in the duodenum, small intestine, and colon. No reaction was detected in the liver. The weak reaction was also seen on cell membranes in the gallbladder and the common bile duct and the pancreatic duct cell membranes were equally positive. In other tissues, positive reactions were shown on the columnar epithelium of the trachea, but not definite in the lung. Similar membrane staining was also detected in the tubular epithelial cells of the kidney and the transitional epithelium of the urinary bladder. No reaction was detected in the lymphoid tissues.

\section{Discussion}

We prepared and selected a monoclonal antibody (McAb F30) directed against the established human pancreatic cancer cell, PK-1. The isotype of the monoclonal antibody was $\mathrm{IgG}_{2 b}$. Since PK-1 cells used for immunization was positive for CEA, $\beta 2$-microglobulin and HLA, it was necessary to clarify whether $\mathrm{McAb}$ F30 is an antibody directed to these antigens. From the results of the binding inhibition assay of ${ }^{125} \mathrm{I}$-labeled McAb F30, it was shown that F30 directed to neither $\beta 2$-microglobulin nor HLA-associated antigens such as shared HLA and HLA-DR antigens (Table 3 ). It is clear that F30 reactive antigen is different from HLA, because F30 failed to react with lymphoblastoid cell lines and normal lymphocytes (Table 1). It is also evident from the data in Table 2 and Fig. 4 that F30 reactive antigen is neither blood type antigens nor fetal bovine serum components. As for the relationship between $\mathrm{F} 30$ reactive antigen and CEA, $\mathrm{McAb}$ F30 was not absorbed with gastric cancer cell line KATO-3 which was strongly CEA positive (Fig. 3). Furthermore, CEA was not co-capped with F30 reactive antigen (Fig. 2). Therefore, it was concluded that $\mathrm{F} 30$ reactive antigen was entirely different from CEA.

F30 strongly reacted with all of six established pancreatic cancer cell lines. In addition to this specific reactivity with pancreatic cancer cells, the monoclonal antibody showed cross reactivity with a colon cancer cell line M7609 and an esophagus cancer cell line TE-1. In addition to that, the absorption test demonstrated cross-reactivities with an esophagus cancer cell line TE-4 and human embryonal lung fibroblast, although these cell lines did not show apparent positive immunofluorescence. On the other hand, McAb F30 failed to react with gastric cancer, hepatoma, lung cancer, brain tumor, melanoma, and breast cancer cell lines listed in Table 1.

Tumor associated antigens of embryonic origin including AFP and CEA have been described in variety of tumors (Gold and Freedman 1965; Abelv 1976; Sega et al. 1979; Pant et al. 1982). Oncofetal antigens of pancreatic cancer have also been described by using xenoantisera specific for fetal pancreas (Banwo et al. 1974 ; Gelder et al. 1978; Hobbs 1980). Metzgar et al. (1982) detected antigens 
of human pancreatic adenocarcinoma cells by several murine monoclonal antibodies. One of these monoclonal antibodies reacted with fetal tissues in addition to pancreatic tumors. Therefore, it is possible that McAb F30 reacts with a kind of oncofetal antigen expressed on PK-1 cells. However, it is too early to conclude that F30-reactive antigen is oncofetal only from the cross-reactivity with cultured embryonic fibroblasts, because the cultured cell line may have aquired antigens which were not present in fetal tissues. Pancreatic oncofetal antigens reported so far have been detected in sera of patients with pancreatic cancer, suggesting that the relevant antigens are secreted or shed from tumor cells (Banwo et al. 1974; Gelder et al. 1978; Hobbs 1980). But the F30-reactive antigen was not detected in the concentrated serum-free spent medium of PK-1 cell culture (Fig.4). Therefore the F30-reactive antigen may be an integral protein in the cell membrane and non-secretory one.

Studies on immunoreactivity with various normal and malignant tissue sections indicated that McAb F30 reacted not only with adenocarcinomas of various organs, but also with normal epithelial cell membranes from various tissues including gastrointestinal organs, respiratory system, aand urinary system (Table 5). This reaction specificity is very similar to that of McAb C50-4 produced by Schmiegel et al. (1985). They also reported McAb CI-P83 against pancreatic cancer with more specific reactivity. The difference in reaction specificity on various epithelial cells raises the possibility that epithelial cell subsets may exist as indicated in several reports (Croghan et al. 1983; Thompson et al. 1983). This tissue distribution of F30-reactive antigen on epithelial cell membranes is closely related to the reaction specificity of McAb F30 with established cancer cell lines. These reaction positive cultured cancer cells may retain the same antigenicity of their original tissue antigen. Since the reaction with $\mathrm{McAb}$ F30 is mostly found in differentiated types of adenocarcinomas both in vitro and in frozen tissue sections, F30-reactive antigen may also have characteristics of differentiation antigen similar to CEA which has been shown to be produced in larger quantities in more differentiated type of adenocarcinomas (Zamcheck 1981). In addition to that, there is a possibility that even a reaction negative tissue may begin to express the tissue associated antigen in accordance with their malignant change. The gastric cancer tissue showed positive reaction while it was negative in the normal gastric mucosa (Table 5). This reaction distribution in various normal tissues is vary similar to reaction specificity of the monoclonal antibody which were shown to be reactive with the differentiation antigen of epithelial cells (Atkinson et al. 1982; Croghan et 1. 1983 ; Menard et al. 1983 ; Thompson et al. 1983).

It is interesting to note that the F30-reactive antigen is not detected in the liver and is not a secreted type antigen, indicating that McAb F30, if conjugated with anti-tumor drugs, may be useful as a specific immunotherapeutic agent to prevent liver metastasis. 
In preliminary molecular characterization of F30-reactive antigen by immnuoprecipitation and SDS-PAGE, two peptide components with molecular weight of $190 \mathrm{k}$ and $160 \mathrm{k}$ were detected. It is not clear why two components are reactive with McAb F30. One possibility is that two components were separated by the treatment with SDS and urea (Mazauric et al. 1982). Alternatively two different components on the cell surface share the same antigenic determinants reactive with McAb F30. One component labeled with ${ }^{35}$ S-methionine was faintly seen and estimated to be approximately $200 \mathrm{k}$ dalton. This $200 \mathrm{~K}$ component may be the same to $190 \mathrm{~K}$ component (Fig. 5). Considering from low sensitivity of F30-reactive antigen to neuraminidase, the antigen does not seem to be associated with sialic acid. Further studies on the characterization of the antigen defined by the monoclonal antibody and the detailed distribution of the antigen in tissues including various malignant and fetal tissues are needed.

\section{Acknowledgments}

We wish to thank Dr. Tetsuro Nishihira, the Second Department of Surgery, Tohoku University School of Medicine, for providing gastric, esophagus, and colon cancer cell lines and Dr. Shunsuke Kobayashi, the Department of Surgery, the Research Institute for Tuberculosis and Cancer, Tohoku University, for providing lung cancer and melanoma cell lines.

\section{References}

1) Abelv, G.I. (1976) Production of serum $\alpha$-globulin in cancer patients-diagnosis value-. Int. J. Cancer, $2,551$.

2) Atkinson, B.F., Ernst, C.S., Herlyn, M., Steplewski, Z., Henry F.S. \& Koprowski, H. (1982) Gastrointestinal Cancer-associated antigen in immunoperoxidase assay. Cancer Res., 42, 4820-4823.

3) Banwo, O., Versey, J. \& Hobbs, J.R. (1974) New oncofetal antigen for human pancreas. Lancet, 1, 643-645.

4) Bernal, D.S. \& Speak, A.J. (1984) Membrane antigen in small cell carcinoma of the lung defined by monoclonal antibody SM1. Cancer Res., 44, 265-270.

5) Brown D.T. \& Moore, M. (1982) Monoclonal antibodies against two human lung carcinoma cell lines. Brit. J. Cancer, 46, 794-802.

6) Bumol, T.F. \& Reisfeld, R.A. (1982) Unique glycoproteinproteoglycan complex defined by monoclonal antibody on human melanoma cells. Proc. nat. Acad. Sci., 79, $1245-1249$.

7) Croghan, G.A., Papsidero, L.D., Valenzuela, A., Nemoto, T., Penetrante, R. \& Chu, T. M. (1983) Tissue distribution of an epithelial and tumor associated antigen recognized by monoclonal antibody F36/22. Cancer Res., 43, 4980-4988.

8) Galloway, D.R., McCabe, R.P., Pellegrino, M.A., Ferrone, S. \& Reisfeld, R.A. (1981) Tumor-associated antigens in spent medium of human melanoma cells: Immunochemical characterization with xenoantisera. J. Immunol., 126, 62-66.

9) Gelder, F.B., Reese, C.J., Moosa, A.R., Hall, T. \& Hunter, R. (1978) Purification, partial characterization, and clinical evaluation of a pancreatic oncofetal antigen. Cancer Res., 38, 313-324.

10) Gold, P. \& Freedman, S.O. (1965) Specific carcinoembryonic antigens of the human digestive system. J. exp. Med., 122, 467-481.

11) Hirohashi, S., Shimosato, Y., Kameya, T., Koide, T., Mukojima, T., Taguchi, Y. \& 
Kageyama, K. (1979) Production of $\alpha$-fetoprotein and normal serum proteins by xenotransplanted human hepatomas in relation to their growth and morphology. Cancer Res., 39, 1819-1828.

12) Hobbs, J.R. (1980) Pancreatic oncofetal antigen (POA) : Its frequency and localization in humans. Oncodev. Biol. Med., 1, 37-48.

13) Holyoke, E.D., Douglass, H.O., Goderosen, M.H. \& Chu, T.M. (1979) Tumor markers in pancreatic cancer. Semin. Oncol. 6, 347-356.

14) Kasai, M., Saxton, R.E., Holmes, E.C., Burk, M.W.\& Morton, D.L. (1981) Membrane antigens detected on human lung carcinoma cell by hybridoma monoclonal antibody. J. Surg. Res., 30, 403-408.

15) Kaszubowski, A.P., Terasaki, I.P., Chia, S.D., Kukes, D.G., Hardiwidjaja, I.S. \& Cicciarelli, C.J. (1984) A cytotoxic monoclonal antibody to colon adenocarcinoma. Cancer Res., 44, 1194-1199.

16) Kobari, M., Matsuno, S., Sato, T., Kan, M. \& Tachibana, T. (1984) Establishment of a human pancreatic cancer cell line and detection of pancreatic cancer associated antigen. Tohoku J. exp. Med., 143, 33-46.

17) Köhler, G. \& Milstein, C. (1975) Continuous cultures of fused cells secreting antibody of predefined specificty. Nature (Lond.), 256, 495-497.

18) Koprowski, H., Steplewski, Z., Mitchell, K., Herlyn, M., Herlyn, D. \& Fuber, P. (1979) Colorectal carcinoma antigens detected by hybridoma antibodies. Somatic Cell Genet., 5, 957-972.

19) Liao, S., Clarke, B.J., Khosravi, M., Kwong, P.C., Brickenden, A. \& Dent, P.B. (1982) Human melanoma-specific oncofetal antigen defined by a mouse monoclonal antibody. Int. J. Cancer, 30, 573-580.

20) Machida, S., Ishioka, T., Takashima, K., Fukushima, M., Ishikawa, Y. \& Kudo, H. (1977) Establishment of a human rectal cancer cell line producing carcinoembryonic antigen. Gann., 68, 775-780.

21) Masuko, T., Abe, J., Yagita, H. \& Hashimoto, Y. (1985) Human bladder cancer cell-surface antigens recognized by murine monoclonal antibodies raised against T24 bladder cancer cell. Gann, 76, 386-394.

22) Mazauric, T., Mitchell, K.F., Letchworth, G.J., Koprowski, H. \& Steplewski, Z. (1982) Monoclonal antibody-defined human lung cell surface protein antigens. Cancer Res., 42, $150-154$.

23) McConahey, P.J. \& Dixon, F.J. (1966) A method of trace iodination of proteins for immunologic studies. Int. Arch. Allergy, 29, 185-189.

24) Menard, S., Tagliabue, E., Canevari, S., Fossati, G. \& Colnaghi, M.I. (1983) Generation of monoclonal antibodies reacting with normal and cancer cells of human breast. Cancer Res., 43, 1295-1300.

25) Metzgar, R.S., Gaillard, M.T., Levine, S.J., Tuck, F.L., Bossen, E.H. \& Borowitz, M. J. (1982) Antigens of human pancreatic adenocarcinoma cells defined by murine monoclonal antibodies. Cancer Res., 42, 601-608.

26) Nakabayashi, H., Taketa, K., Yamane, T., Miyazaki, M., Miyano, K. \& Sato, T. (1984) Phenotypical stability of a human hepatoma cell line, HuH-7, in long-term culture with chemically defined medium. Gann, 75, 151-158.

27) Natari, P.G., Wilson, B.S., Imai, K., Bigotti, A. \& Ferrone, S. (1982) Tissue distribution, molecular profile, and shedding of a cytoplasmic antigen identified by the monoclonal antibody 465.12S to human melanoma cells. Cancer Res., 42, 583-589.

28) Nishihira, T., Kasai, M., Mori, S., Watanabe, T., Kuriya, Y., Suda, M., Kitamura, M., Hirayama, K., Akaishi, T. \& Sasaki, T. (1979) Characterization of two cell lines (TE-1 and TE-2) derived from human squamous cell carcinoma of the esophagus. Gann, 70, 575-584.

29) Pant, K.D., Shochat, D., Nelson, M. \& Goldenberg, M. (1982) Initial clinical evaluation as a marker for colorectal cancer. Cancer, 50, 919-926. 
30) Papsidero, L.D., Croghan, G.A., O’Connell, M.J., Vakenzuela, L.A., Nemoto, T. \& Chu, T.M. (1983) Monoclonal antibodies (F36/22 and M7/105) to human breast carcinoma. Cancer Res., 43, 1741-1747.

31) Schmiegel, H.W., Kalthoff, H., Arndt, R., Gieseking, J., Greten, H., Klöppel, G., Kreiker, C., Ladak, A., Lampe, V. \& Ulrich, S. (1985) Monoclonal antibody-defined human pancreatic cancer-associated antigens. Cancer Res. 45, 1402-1407.

32) Schultz, D.R. \& Yunis, A.A. (1976) Tumor-associated antigen in human pancreatic cancer. J. nat. Cancer Inst., 62, 777-785.

33) Sega, E., Citro, G. \& Natali, P.G. (1979) Partial characterization of fetal lung antigen associated with human bronchogenic carcinoma. J. nat. Cancer Inst., 62, $1125-1130$.

34) Sekiguchi M., Sakakibara, K. \& Fujii, G. (1978) Establishment of cultured cell lines derived from a human gastric carcinoma. Jap. J. exp. Med., 48, 61-68.

35) Starling, J.J., Sieg, S.M., Beckett, M.L., Schellhammer, P.F., Ladaga, L.E. \& Wright, G.L., Jr. (1982) Monoclonal antibodies to human prostate and bladder tumorassociated antigens. Cancer Res. 42, 3084-3089.

36) Steplewski, Z., Herlyn, M., Herlyn, D., Clark, W.H. \& Koprowski, H. (1979) Reactivity of monoclonal anti-melanoma antibodies with melanoma cells freshly isolated from primary and metastatic melanoma. Europ. J. Immunol., 9, 94-96.

37) Thompson, C.H., Jones, S.L., Phil, E. \& Mckenzie, I.F.C. (1983) Monoclonal antibodies to human colon and colorectal cacinoma. Brit J. Cancer, 47, 595-605.

38) Wood, R.A.B. \& Moosa, A.R. (1978) The prospective evaluation of tumor associated antigens for early diagnosis of pancreatic cancer.Brit. J. Surg., 64, 718-729.

39) Zamcheck, N. (1981) The expanding field of colorectal cancer markers: CEA, the prototype. Cancer Bull. 33, 141. 